Irwansah, Sugiyarto, Edwi Mahajoeno. (2019). Struktur Komunitas Ekosistem Mangrove di eluk Serewe Pulau Lombok Nusa Tenggara Barat. Journal Bioeksperimen. Vol. 5 (2) Pp. 126-130. Doi: 10.23917/bioeksperimen.v5i2.2795

\title{
STRUKTUR KOMUNITAS EKOSISTEM MANGROVE DI TELUK SEREWE PULAU LOMBOK NUSA TENGGARA BARAT
}

\author{
Irwansah*, Sugiyarto, Edwi Mahajoeno \\ Magister Biosain, Pascasarjana, Universitas Sebelas Maret \\ *E-mail: irwansah8007@gmail.com \\ Paper diterima : 22 Juni 2018, Paper publish : September 2019
}

\begin{abstract}
The purpose of this study is to obtain the value of density, frequency, mangrove cover and the mangrove importance index (INP Mangrove) The method used for belt transects. The quadratic transect method measures $10 \mathrm{~m} \times 10 \mathrm{~m}$ (tree category), $5 \mathrm{~m} \times 5 \mathrm{~m}$ (sapling category) and $2 \mathrm{~m} \times 2 \mathrm{~m}$ (seedling category). The results found that the mangrove community in Serewe Bay, Lombok Island, West Nusa Tenggara. Tree strata are dominated by Sonneratia alba species, pole strata are dominated by Sonneratia alba species and the seedling strata are dominated by Pemphis acidula. This shows that the existence of these three types can be found in almost every plot / plot. The Importance Value Index (INP) of mangroves obtained is classified as moderate, this shows that mangroves in Serewe Bay, Lombok Island, West Nusa Tenggara have an important role for the coastal environment.
\end{abstract}

Keywords: Community Structure, Mangroves, Serewe Bay, Lombok Island

\section{Pendahuluan}

Hutan mangrove umumnya terdapat di seluruh pantai Indonesia dan hidup serta tumbuh berkembang pada lokasi-lokasi yang mempunyai hubungan pengaruh pasang surut yang merembes pada aliran sungai yang terdapat di sepanjang pesisir pantai (Tarigan, 2008). Mangrove hanya dapat ditemui di daerah tropik dan subtropik. Mangrove yang merupakan khas daerah tropis, hidupnya hanya mampu berkembang baik di temperatur $19^{\circ} \mathrm{C}$ sampai $40^{\circ} \mathrm{C}$ dengan toleransi fluktuasi tidak lebih dari $10^{\circ} \mathrm{C}$. Berbagai jenis mangrove tumbuh di bibir pantai dan menjorok ke zona berair laut. Pola hidup mangrove ini merupakan suatu fenomena yang khas, dikarenakan tidak ada tanaman selain mangrove yang mampu bertahan hidup di zona peralihan darat dan laut layaknya pola hidup mangrove (Irwanto, 2006).

Selain itu, ekosistem mangrove juga memiliki produktivitas tinggi sehingga mampu menyediakan makanan berlimpah bagi berbagai jenis hewan laut dan menyediakan tempat berkembang biak, memijah, dan membesarkan anak bagi beberapa jenis ikan, kerang, kepiting dan udang. Dedaunan, ranting, bunga, dan buah dari tanaman mangrove yang mati dimanfaatkan oleh makrofauna, misalnya kepiting sesarmid, dan kemudian didekomposisi oleh berbagai jenis mikroba yang melekat di dasar mangrove dan secara bersama-sama membentuk rantai makanan (Gunarto, 2004).

Komunitas mangrove dinilai sangat penting keberadaannya karena fungsinya yang sangat beragam, diantaranya adalah sebagai pelindung pantai dari hempasan ombak dan angin kencang, penahan abrasi, penampung air hujan sehingga dapat mencegah banjir, dan penyerap limbah yang mencemari perairan. Oleh karena itu secara tidak langsung kehidupan manusia tergantung pada keberadaan ekosistem mangrove (Pirzan dkk, 2001).

Mangrove yang ada di Teluk Serewe Pulau Lombok Nusa Tenggara Barat luasnya mencapai 8 ha Salah satu teluk yang ada di desa serewe kecamatan jerowaru kabupaten Lombok Timur. Mangrove yang ada di Teluk Serewe masih terjaga kealamiannya. Hal ini dapat dibuktikan dari observasi yang dilakukan, bahwa tumbuhan mangrove banyak dijumpai di sekitar teluk. Masih dibutuhkan penelitian-penelitian lebih 
lanjut dalam rangka pengelolaan kawasan ini, apalagi kawasan in merupakan daerah wisata alam . Untuk itu, dipandang perlu untuk mengadakan penelitian tentang struktur komunitas ekosistem mangrove di Teluk Serewe Pulau Lombok Nusa Tenggara Barat.

Tujuan penelitian ini adalah untuk mengetahui struktur dan komposisi vegetasi yang berada di hutan mangrove di Teluk Serewe Pulau Lombok.

\section{Metode Penelitian}

\section{Waktu dan Tempat}

Penelitian dilakukan padabulan NopemberDesember 2016 yang ditentukan menggunakan metode Transek Sabuk (Belt Transect), yaitu di Teluk Serewe Pulau Lombok Nusa Tenggara Barat berada pada posisi koordinat $S$ 8'53'32.5428” dan E 116³0'16.3764”.

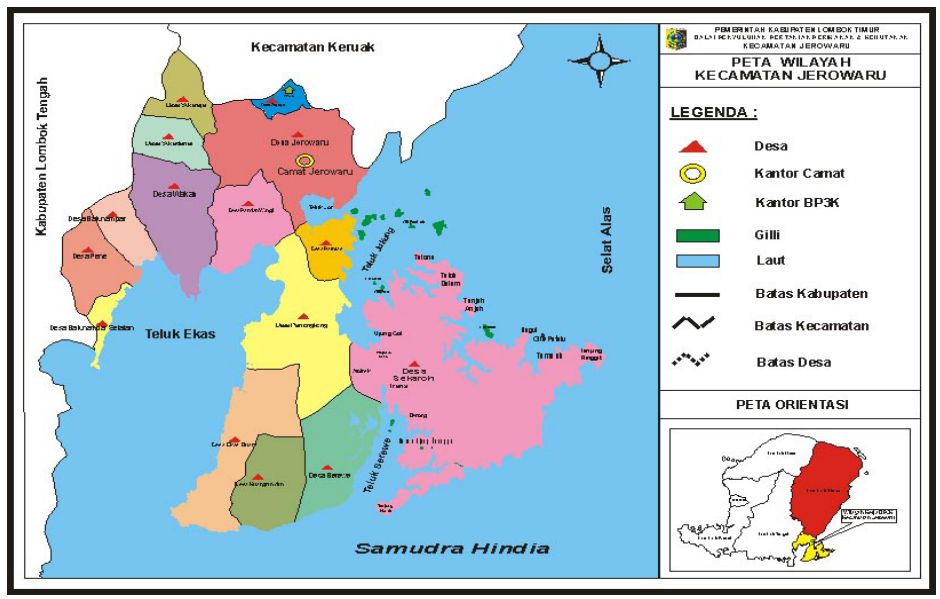

Gambar 2. Lokasi Penelitian di Teluk Serewe Pulau Lombok Nusa Tenggara Barat

\section{Alat dan Bahan}

Alat dan bahan yang digunakan dalam penelitian ini adalah patok kayu, meteran/ rol meter, GPS, buku Pengenalan Mangrove Indonesia (Noor dkk., 2006), kamera digital, alat tulis serta, laptop.

\section{Analisis Data}

Observasi dilakukan terhadap jenis vegetasi yang tumbuh di kawasan pantai dan pesisir. Salah satu kelompok vegetasi yang dominan adalah mangrove. Data tumbuhan mangrove diperoleh dengan membuat 40 plot di setiap lokasi penelitian. Pada masing-masing plot dibuat 3 petak ukur, yaitu $10 \times 10 \mathrm{~m}$ (untuk pohon), 5 × $5 \mathrm{~m}$ (pancang), dan $2 \times 2 \mathrm{~m}$ (untuk semai).

Struktur Komunitas Mangrove dilakukan dengan menganalisis parameter dengan mengacu pada SNI 7717 tahun 2011 tentang survey dan pemetaan mangrove.. Perhitungan besarnya nilai kuantitif parameter vegetasi, khususnya dalam penentuan indeks nilai penting, dilakukan dengan formula (Onrizal, 2008) berikut ini:

a. Kerapatan jenis $(\mathrm{K})$

$$
K i=\frac{n i}{A}
$$

Keterangan:

$\mathrm{Ki}=$ Kerapatan jenis ke- $\mathrm{i}$

$\mathrm{Ni}=$ Jumlah total individu dari jenis ke-i

$A=$ Luas area total pengambilan Sampel $\left(\mathrm{m}^{2}\right)$

b. Kerapatan relatif suatu jenis (KR)

$K R=\frac{n i}{\Sigma n} \times 100$

Keterangan:

$\mathrm{KR}$ = Kerapatan relative jenis

ni = Jumlah total individu dari jenis ke-i

$\Sigma \mathrm{n}=$ Jumlah total tegakan seluruh jenis

c. Frekuensi suatu jenis (F)

$F i=\frac{P i}{\Sigma P}$

Keterangan:

$\mathrm{Fi}=$ Frekuensi Relatif jenis ke- $\mathrm{i}$

$\mathrm{Pi}=$ Jumlah petak dimana ditemukan jenis ke-i

$\Sigma \mathrm{P}=$ Jumlah total petak sampel yang dibuat

d. Frekuensi relatif suatu jenis (FR)

$F R=\frac{F i}{\Sigma F} x 100$

Irwansah, Sugiyarto, Edwi Mahajoeno-127 
Keterangan:

$\mathrm{FR}=$ Frekuensi relatif

$\mathrm{Fi}=$ Frekuensi jenis $\mathrm{k}-\mathrm{i}$

$\Sigma \mathrm{F}=$ Jumlah frekuensi untuk seluruh jenis

e. Dominansi suatu jenis (D). D hanya dihitung untuk tingkat pohon.

$$
D i=\frac{\text { luas total penutupan } k e-i}{\text { luas total pengambilan sampel }}
$$

f. Dominansi relatif suatu jenis (DR)

$$
D R=\frac{\text { penutupan } k e-i}{\text { penutupan seluruh jenis }} \times 100
$$

g. Indeks Nilai Penting (INP)

Rumus yang digunakan untuk menghitung INP sebagai berikut, Saparinto (2007):

$\mathrm{INP}=\mathrm{KR}+\mathrm{FR}+\mathrm{DR}$

Keterangan :

INP = Indeks Nilai Penting

$\mathrm{DR}=$ Dominasi Relatif

$\mathrm{FR}=$ Frekuensi Relatif

$\mathrm{KR}=$ Kerapatan Relatif

\section{Hasil dan Pembahasan}

Berdasarkan pengamatan di wilayah Teluk Serewe terdapat 8 famili dengan 8 jenis tumbuhan

Tabel 1. Hasil analisa vegetasi tingkat semai

\begin{tabular}{clccc}
\hline No. & \multicolumn{1}{c}{ Nama Tumbuhan } & KR\% & FR\% & INP\% \\
\hline 1 & Pemphis acidula & 23.86 & 25.00 & 48.86 \\
2 & Sesuvium portulacastrum & 22.73 & 18.75 & 41.48 \\
3 & Sonneratia alba & 13.64 & 15.63 & 29.26 \\
4 & Rhizophora mucronata & 9.09 & 9.38 & 18.47 \\
5 & Dolichandrone spathacea & 9.09 & 9.38 & 18.47 \\
6 & Avicennia officinalis & 6.82 & 9.38 & 16.19 \\
7 & Ricinus communis & 6.82 & 6.25 & 13.07 \\
8 & Casuarina equisetifolia & 4.55 & 3.13 & 7.67 \\
9 & Hibiscus tiliaceus & 3.41 & 3.13 & 6.53 \\
\hline Jumlah & & 100 & 100 & 200 \\
\hline
\end{tabular}

Mangrove pada tingkat semai ditemukan 9 spesies mangrove yaitu 6 Mangrove Sejati dengan kerapatan relative tertinggi didominasi oleh pemphis acidula (23.86), kerapatan relative terendah yaitu Hibiscus tiliaceus (3.41). Frekuensi relative tertinggi yaitu Pemphis acidula (25.00) dan frekuensi terendah yaitu Hibiscus tiliaceus dan Casuarina equisetifolia sama-sam (3.13) (Tabel 1). Parameter INP (Indeks Nilai Penting), berdasarkan pendapat yang dikemukakan oleh Sutisno (1993) bahwa tingkatan vegetasi (sapihan dan semai) suatu jenis dapat dikatakan berperan jika INP > 10\%. Dengan demikian jenis-jenis yang memiliki INP yang berperan penting adalah jenis $R$. mucronata, S.alba, A.officinalis, D.spathacea, R.communis, Pemphis acidula, dan S.portulacastrum. dengan nilai INP antara 13.07-48.86. Nilai ini mengindikasikan bahwa jenis mangrove tersebut mempengaruhi kestabilan ekosistem.

Tingkat pancang ditemukan 7 spesies yaitu 5 mangrove sejati dengan kerapatan relative tertinggi Sonneratia alba (27.11), kerapatan terendah yaitu Hibiscus tiliaceus (12.05). Frekuensi relative tertinggi yaitu Sonneratia alba (25.00), Frekuensi relative terendah yaitu Hibiscus tiliaceus (6.25). Dominasi relative tertinggi yaitu Rhizopora mucronata (21.21), dan Dominasi relative terendah yaitu Hibiscus tiliaceus (6.56). Jenis yang memiliki INP tertinggi merupakan jenis yang sangat mempengaruhi suatu komunitas tumbuhan. 
Tabel 2 analisis vegetasi tingkat pancang

\begin{tabular}{clcccc}
\hline No. & \multicolumn{1}{c}{ Nama Tumbuhan } & KR (\%) & FR (\%) & DR (\%) & INP\% \\
\hline 1 & Rhizophora mucronata & 19.64 & 12.50 & 21.12 & 53.26 \\
2 & Ricinus communis & 19.64 & 3.13 & 18.09 & 40.86 \\
3 & Avicennia officinalis & 30.12 & 6.25 & 18.45 & 54.82 \\
4 & Sonneratia alba & 27.11 & 25.00 & 17.17 & 69.28 \\
5 & Casuarina equisetifolia & 18.07 & 6.25 & 9.64 & 33.96 \\
6 & Dolichandrone spathacea & 15.06 & 9.38 & 8.97 & 33.41 \\
7 & Hibiscus tiliaceus & 12.05 & 6.25 & 6.56 & 24.86 \\
\hline Jumlah & & 141.69 & 68.76 & 100 & 311 \\
\hline
\end{tabular}

Berdasarkan hasil perhitungan ditemukan jenis yang berperan dalam komunitas tumbuhan yaitu S. alba dengan nilai 69.28. Dengan demikian jenis tersebut merupakan jenis yang paling mempengaruhi komunitas tumbuhan, jenis-jenis tersebut berdampak besar terhadap kestabilan ekosistem karena memiliki kerapatan yang cukup tinggi dan penyebaran yang luas.
Sedangkan yang tergolong dalam nilai INP rendah terdapat pada $H$. tiliaceus dengan nilai 24.86. Hal ini menunjukkan bahwa merupakan jenis yang kritis karena disusun oleh kerapatan, frekuensi dan dominasi yang kecil yang berarti jenis-jenis tersebut sangat potensial untuk hilang dari ekosistem hutan mangrove karena tingkat keberadaannya yang juga sangat rendah.

Tabel 3 analisis vegetasi tingkat pohon

\begin{tabular}{clcccc}
\hline No. & \multicolumn{1}{c}{ Nama Tumbuhan } & KR (\%) & FR (\%) & DR (\%) & INP\% \\
\hline 1 & Sonneratia alba & 63.33 & 21.82 & 81.23 & 166.38 \\
2 & Dolichandrone spathacea & 11.33 & 9.09 & 3.60 & 24.02 \\
3 & Rhizophora mucronata & 9.33 & 7.27 & 6.84 & 23.44 \\
4 & Avicennia officinalis & 7.33 & 9.09 & 3.52 & 19.94 \\
5 & Casuarina equisetifolia & 3.33 & 12.73 & 3.99 & 20.05 \\
6 & Hibiscus tiliaceus & 2.67 & 5.45 & 0.65 & 8.77 \\
7 & Ricinus communis & 2.67 & 3.64 & 0.74 & 7.05 \\
\hline \multicolumn{2}{c}{ Jumlah } & 99.99 & 69.09 & 100.57 & 290 \\
\hline
\end{tabular}

Berdasarkan hasil penelitian di Teluk Serewe Pulau Lombok Nusa Tenggara Barat pada tingkat pohon ditemukan 7 spesies yaitu 5 mangrove sejati dengan Indeks nilai penting (INP) merupakan nilai yang menggambarkan peranan kerapatan relatif tertinggi yaitu $S$. alba (63.33), kerapatan relatif terendah yaitu $R$. Communis (2.67). frekuensi relatif tertinggi yaitu S. alba (21.82), frekuensi relatif terendah yaitu $R$. communis (3.64), dominasi relatif tertinggi $S$. alba (81.23), dominasi relatif terendah yaitu (0.74). Jenis yang memiliki INP tertinggi merupakan jenis yang sangat mempengaruhi suatu komunitas tumbuhan. Nilai Penting tertinggi pada tingkat pohon ditemukan pada jenis S.alba dengan nilai 166.38 , D.spathacea dengan nilai 24.02 , R.mucronata dengan nilai 23.44 dan C.equisetifolia dengan nilai 20.05 dan A.officinalis dengan nilai 19.94. Parameter Indeks Nilai Penting, berdasarkan pendapat yang dikemukakan oleh Sutisno (1993) bahwa tingkatan vegetasi (pohon) suatu jenis dapat dikatakan berperan jika INP > 15\%. Jenis tersebut tergolong memiliki peran untuk komunitas jenis mangrove yang tumbuh disekitarnya. Nilai ini mengindikasikan bahwa jenis-jenis tersebut mempengaruhi kestabilan ekosistem. Keempat jenis tersebut merupakan jenis yang paling mempengaruhi komunitas, hilangnya spesies-spesies ini akan berdampak 
besar terhadap kestabilan ekosistem. Penabangan pohon secara besar-besaran pada ketiga spesies ini akan menciptakan ruang yang luas di antara tajuk karena memiliki kerapatan yang sangat tinggi, penyebaran yang luas, dan ukuran pohon yang besar, sehingga memungkinkan munculnya spesies lain yang dominan. Hal ini sejalan dengan Bengen (2001) menyatakan bahwa nilai penting berkisar antara 0-300. Ini memberikan gambaran bahwa semakin besar nilai indeks nilai penting suatu jenis memberikan gambaran besarnya sumberdaya lingkungan yang dimanfaatkan oleh jenis tersebut dalam pertumbuhannya. Sedangkan yang tergolong dalam nilai INP rendah terdapat pada $H$. tiliaceus dan R.communis. Hal ini menunjukkan bahwa kedua jenis tersebut merupakan jenis yang kritis karena disusun oleh kerapatan, frekuensi dan dominasi yang kecil dengan nilai INP kurang dari $15 \%$ yang berarti jenis-jenis tersebut sangat rentan untuk hilang dari ekosistem hutan mangrove karena tingkat keberadaannya yang sangat rendah.

\section{Simpulan}

Struktur jenis vegetasi yang berada di hutan mangrove di Teluk Serewe Pulau Lombok parameter Indeks Nilai Penting (INP) untuk tingkat semai di dominasi oleh Pemphis acidula (53.26). Indeks Nilai Penting untuk tingkat pancang didominasi oleh Sonneratia alba (69.28) dan Indeks Nilai Penting untuk tingkat pohon di dominasi oleh Sonneratia alba (166.38).

\section{Referensi}

Bengen, D.G. 2001. Ekosistem dan sumberdaya alam pesisir laut. Pusat Kajian Sumberdaya Pesisir dan Lautan IPB: 25 hal.

Gunarto, 2004. Konservasi Mangrove Sebagai Pendukung Sumber Hayati Perikanan Pantai. Jurnal Litbang Pertanian, 23(1).

Noor, R.Y., M. Khazali, dan I.N.N. Suryadiputra. 2006. Panduan Pengenalan Mangrove di Indonesia.PHKA/WI-IP. Bogor.

Irwanto, 2006. Keanekaragaman Fauna pada Habitat Mangrove. Yogyakarta. (http://www. irwantoshut.com/) diakses 20 Mei 2017.

Pirzan, A.M., D. Rohama, Utojo, Burhanuddin, Suharyanto, Gunarto, dan H.Padda. 2001.Telaah biodiversitas di kawasan tambak dan mangrove. Laporan Akhir Proyek Inventarisasi dan Evaluasi Sumber Daya Perikanan Pesisir. Balai Penelitian Perikanan Pantai, Maros. 37 hlm.

Tarigan M., S., 2008. Sebaran dan Luas Hutan Mangrove di Wilayah Pesisir Teluk Pising Utara Pulau Kabaena Provinsi Sulawesi Tenggara, makara, sains, vol. 12, no. 2, november 2008: 108-112, Bidang Dinamika Laut, Pusat Penelitian Oseanografi, LIPI, Jakarta 14430, Indonesia.

Wibowo, K. dan Handayani, T., (2006). Pelestarian Hutan Mangrove melalui Pendekatan Mina Hutan (Silvofishery). Jurnal Teknik Lingkungan,7 (3), 135-137. 